NIEBUHR, Pedro de Menezes; OLIVEIRA, Cláudio Ladeira de; QUINT, Gustavo Ramos da Silva. Relação entre a consensualidade administrativa e o modelo cooperativo do processo civil brasileiro: o contexto de criação das câmaras de mediação e conciliação na administração pública. Revista Eletrônica Direito e Política, Programa de Pós-Graduação Stricto Sensu em Ciência Jurídica da UNIVALI, Itajaí, v.13, n.3, $3^{\circ}$ quadrimestre de 2018. Disponível em: www.univali.br/direitoepolitica - ISSN 1980-7791

\title{
RELAÇÃO ENTRE A CONSENSUALIDADE ADMINISTRATIVA E O MODELO COOPERATIVO DO PROCESSO CIVIL BRASILEIRO: O CONTEXTO DE CRIAÇÃO DAS CÂMARAS DE MEDIAÇÃO E CONCILIAÇÃO NA ADMINISTRAÇÃO PÚBLICA
}

\author{
RELATIONSHIP BETWEEN ADMINISTRATIVE CONSENSUITY AND THE \\ COOPERATIVE MODEL OF THE BRAZILIAN CIVIL PROCESS: THE CONTEXT OF \\ CREATION OF THE MEDIATION AND CONCILIATION CHAMBERS IN THE PUBLIC \\ ADMINISTRATION
}

\author{
Pedro de Menezes Niebuhr ${ }^{1}$ \\ Cláudio Ladeira de Oliveira² \\ Gustavo Ramos da Silva Quint ${ }^{3}$
}

\begin{abstract}
SUMÁRIO: Introdução; 1 A "Queda do Muro de Berlim" da Administração Pública: Uma Abertura À Consensualidade; 2Mudança de paradigma no processo civil brasileiro: a cooperação no Código de Processo Civil de 2015 e as câmaras de mediação e conciliação na Administração Pública como expressão da consensualidade; 2.1 Os modelos processuais e a cooperação no Código de Processo Civil; 2.2 Pontos de contato entre o Direito Processual Civil e o Direito Administrativo: as câmaras de conciliação e mediação com a Administração Pública; 2.3 A Lei no 13.140/15; Considerações Finais;

Referências das Fontes Citadas.
\end{abstract}

\section{RESUMO}

O artigo aborda a nova postura da Administração Pública a partir do fenômeno da consensualidade, observada pela releitura de alguns dos institutos clássicos do Direito Administrativo. Sugere-se uma relação desse novo agir com o modelo cooperativo sedimentado pelo Código de Processo Civil, com ênfase nos mecanismos consensuais de solução de conflitos, em especial, a mediação e a

\footnotetext{
1 Professor dos Programas de Graduação e Pós-graduação em Direito da Universidade Federal de Santa Catarina, Florianópolis, Santa Catarina, Brasil. Doutor em Direito pela Pontifícia Universidade Católica do Rio Grande do Sul, com estágio de doutoramento (CAPES) na Universidade de Lisboa. Coordenador do Grupo de Estudos em Direito Público - GEDIP/UFSC. Email: pedro.n@ufsc.br

2 Professor dos Programas de Graduação e Pós-graduação em Direito da Universidade Federal de Santa Catarina, Florianópolis, Santa Catarina, Brasil. Doutor em Direito pela Universidade Federal de Santa Catarina, Florianópolis. Coordenador do Grupo de Pesquisas em Constitucionalismo Político da Universidade Federal de Santa Catarina, Florianópolis. Email: claudioladeiradeoliveira@gmail.com

3 Mestrando em Direito Administrativo pela Universidade Federal de Santa Catarina. Bacharel em Direito Pela UFSC. Advogado e membro fundador do Grupo de Estudos em Direito Público GEDIP/UFSC. Email: gustavorsq@gmail.com
} 
NIEBUHR, Pedro de Menezes; OLIVEIRA, Cláudio Ladeira de; QUINT, Gustavo Ramos da Silva. Relação entre a consensualidade administrativa e o modelo cooperativo do processo civil brasileiro: o contexto de criação das câmaras de mediação e conciliação na administração pública. Revista Eletrônica Direito e Política, Programa de Pós-Graduação Stricto Sensu em Ciência Jurídica da UNIVALI, Itajaí, v.13, n.3, $3^{0}$ quadrimestre de 2018. Disponível em: www.univali.br/direitoepolitica - ISSN 1980-7791

conciliação. Examinam-se as previsões atinentes às câmaras de conciliação e mediação na Administração Pública, bem como o regramento próprio da mediação e da autocomposição de litígios nesta seara, apontando-se algumas possibilidades e limitações. Conclui-se que o Código de Processo Civil vai ao encontro do novo paradigma administrativo, ao tornar obrigatória a existência de câmaras de conciliação e mediação para facilitar a autocomposição de litígios. 0 método de pesquisa utilizado é dedutivo, com base em pesquisa bibliográfica.

PALAVRAS-ChaVe: Administração Pública consensual. Cooperação. Processo Civil. Mediação. Conciliação.

\section{ABSTRACT}

The article approaches the new posture of the Public Administration from the phenomenon of consensuality, observed by the re-reading of some of the classic institutes of Administrative Law. It is suggested a relation of this new action with the cooperative model established by the Civil Process Code, with emphasis in the consensual mechanisms of solution of conflicts, in particular, the mediation and the conciliation. The provisions of the conciliation and mediation chambers in the Public Administration are examined, as well as the proper regulation of mediation and self-determination of litigation in this area, pointing out some possibilities and limitations. It is concluded that the Civil Process Code meets the new administrative paradigm, making mandatory the existence of conciliation and mediation chambers to facilitate the self-determination of litigation. The research method used is deductive, based on bibliographic research.

KEYWORDS: Consensual Public Administration. Cooperation. Civil Process. Mediation. Conciliation.

\section{INTRODUÇÃO}

O Direito Administrativo vem passando, nas últimas décadas, por inúmeras e sucessivas transformações. Ainda que variando entre saltos largos e singelos passos, o ponto é que a atividade administrativa está em constante processo de evolução. Como bem ressalta Odete Medauar, o "Direito Administrativo hoje estudado não é o mesmo Direito administrativo elaborado até o fim da década de 70 do século $X X^{\prime \prime} .^{4}$

A causa dessas transformações deve-se, em larga medida, à multiplicidade e complexidade das relações na sociedade, que impõem ao Estado a necessidade de revisitar formas de atuação clássicas, convencionais, para responder desafios

\footnotetext{
4 MEDAUAR, Odete. O direito administrativo em evolução. 3. ed. Brasília, DF: Gazeta Jurídica, 2017. p. 389.
} 
NIEBUHR, Pedro de Menezes; OLIVEIRA, Cláudio Ladeira de; QUINT, Gustavo Ramos da Silva. Relação entre a consensualidade administrativa e o modelo cooperativo do processo civil brasileiro: o contexto de criação das câmaras de mediação e conciliação na administração pública. Revista Eletrônica Direito e Política, Programa de Pós-Graduação Stricto Sensu em Ciência Jurídica da UNIVALI, Itajaí, v.13, n.3, $3^{\circ}$ quadrimestre de 2018. Disponível em: www.univali.br/direitoepolitica - ISSN 1980-7791

atuais. Uma vertente de enfrentamento se dá na relação Administraçãoadministrado, ou seja, na superação da noção de "indivíduo como súdito, não como cidadão". 5

A dinâmica processual segue essa tônica. O Código de Processo Civil de 2015 deu especial relevo à cooperação e à adoção de mecanismos consensuais de autocomposição para solução de litígios - dentre os quais serão objetos deste artigo a mediação e a conciliação - como alternativa à força e à imposição.

As linhas que se seguem têm por objetivo demonstrar a relação entre a cooperação no âmbito processual civil com a consensualidade no Direito Administrativo. Pretende-se, através de uma abordagem teórica e bibliográfica, enfrentar o problema consistente em identificar quais seriam os fundamentos do uso da mediação e conciliação no âmbito administrativo, notadamente através da fórmula consagrada pelo Código de Processo Civil de 2015. A hipótese de trabalho é que a previsão, no Código de Processo Civil de 2015, da obrigatoriedade da criação de câmaras de mediação e arbitragem na Administração Pública é consentânea a um novo modelo de atuação administrativa, voltada para o diálogo, participação e envolvimento do cidadão na tomada de decisões.

O método de pesquisa empregado é o dedutivo.

\section{A "QUEDA DO MURO DE BERLIM" DA ADMINISTRAÇÃO PÚBLICA: UMA ABERTURA À CONSENSUALIDADE}

Muitos dos institutos clássicos do Direito Administrativo tem passado por um paulatino processo de revisitação e renovação, ganhando nova roupagem e significação à medida que se reposiciona a relação Administração-administrado.

José Sérgio da Silva Cristóvam ressalta que a postura anterior da Administração Pública, na concepção tradicional do Direito Administrativo, caracterizava-se principalmente por uma posição privilegiada em relação ao cidadão, marcada por um conjunto vasto de prerrogativas, tais quais a presunção de legitimidade

\footnotetext{
${ }^{5}$ MEDAUAR, Odete. 0 direito administrativo em evolução. p. 284.
} 
NIEBUHR, Pedro de Menezes; OLIVEIRA, Cláudio Ladeira de; QUINT, Gustavo Ramos da Silva. Relação entre a consensualidade administrativa e o modelo cooperativo do processo civil brasileiro: o contexto de criação das câmaras de mediação e conciliação na administração pública. Revista Eletrônica Direito e Política, Programa de Pós-Graduação Stricto Sensu em Ciência Jurídica da UNIVALI, Itajaí, v.13, n.3, $3^{\circ}$ quadrimestre de 2018. Disponível em: www.univali.br/direitoepolitica - ISSN 1980-7791

e veracidade de atos administrativos, privilégios processuais judiciais, posição contratual verticalizada, entre outras ${ }^{6}$.

Esse modo de agir da Administração Pública se mostrou inadequado para a solução de problemas dinâmicos e complexos. É nesse contexto que a participação e a consensualidade, como anota Diogo de Figueiredo Moreira Neto, emergem como fatores decisivos nas democracias contemporâneas, por aprimorarem a governabilidade, propiciarem meios de conter abusos, garantirem atenção a todos interesses, viabilizarem decisões mais sábeis e prudentes, desenvolverem senso de responsabilidade das pessoas e tornarem os comandos estatais mais aceitáveis e facilmente obedecidos. Em função de tais características, a consensualidade aparece como alternativa preferível à imperatividade, inclusive na solução de conflitos ${ }^{7}$.

Para Luciano Parejo Alfonso, na sociedade atual, desenvolvida, informada, adulta e completa, o modelo de atuação típico do Direito Administrativo não pode ser o de Administração autoritária ou de intervenção. Para o autor, não se trata de negar ou defender o desaparecimento por completo do poder coertivo, mas de demandar seu exercício de forma diferente, mais refinada e sutil ${ }^{8}$.

De uma atividade administrativa orientada pela lógica de autoridade, pelo ato administrativo impositivo e unilateral, bem como pela preponderância de poderes e prerrogativas exorbitantes, hoje passa-se a adotar e a inserir paulatinamente a lógica de consensualidade, pautada pela negociação e bilateralidade. Abandona-se, aos poucos, a postura verticalizada e hierárquica da Administração Pública em relação aos particulares, para com eles consensualmente e de forma horizontal construir a melhor solução para o caso concreto. ${ }^{9}$

\footnotetext{
${ }^{6}$ CRISTÓVAM, José Sérgio da Silva. Administração pública democrática e supremacia do interesse público: novo regime jurídico-administrativo e seus princípios constitucionais estruturantes. Curitiba: Juruá, 2015. p. 245.

7 MOREIRA NETO, Diogo de Figueiredo. Mutações do Direito Administrativo. Rio de Janeiro: Renovar, 2000. p. 37-43.

8 ALFONSO, Luciano Parejo. Derecho Administrativo. Barcelona: Ariel, 2003. p. 45.

9 SCHIRATO, Vitor Rhein. PALMA, Juliana Bonacorsi de. Consenso e Legalidade: vinculação da Atividade Administrativa Consensual ao Direito. Revista Eletrônica sobre a Reforma do Estado
} 
NIEBUHR, Pedro de Menezes; OLIVEIRA, Cláudio Ladeira de; QUINT, Gustavo Ramos da Silva. Relação entre a consensualidade administrativa e o modelo cooperativo do processo civil brasileiro: o contexto de criação das câmaras de mediação e conciliação na administração pública. Revista Eletrônica Direito e Política, Programa de Pós-Graduação Stricto Sensu em Ciência Jurídica da UNIVALI, Itajaí, v.13, n.3, $3^{\circ}$ quadrimestre de 2018. Disponível em: www.univali.br/direitoepolitica - ISSN 1980-7791

Nesse ínterim, surge, portanto, importante preocupação com o estudo do que se entende por consensualidade na Administração Pública, instituto que se mostra cada vez mais atual, na medida em que também representa uma mudança de paradigma de uma Administração monológica para dialógica. ${ }^{10}$

Em linhas gerais e em sentido amplo, entende-se por consensualidade "qualquer forma de acordo de vontades da Administração Pública, abrangendo indistintamente acordos judiciais, acordos intragovernamentais e os contratos administrativos em geral". ${ }^{11}$

O sentido da consensualidade também pode reverberar na participação do particular na tomada de decisões pela Administração Pública. ${ }^{12} \mathrm{~A}$ respeito deste último sentido ampliado, Gustavo Justino de Oliveira entende que a consensualidade também está atrelada à concepção de uma "Administração mediadora", cujo papel é inserir os cidadãos em um "processo de determinação e densificação do interesse público, o qual deixa de ser visto como um monopólio estatal". ${ }^{13}$

Mudança tal, todavia, adianta-se, não pressupõe que a Administração Pública deve dispor totalmente de suas prerrogativas e de seus poderes; a consensualidade é, na verdade, mais uma solução com o fito de otimizar a atividade administrativa. A respeito dessa nova postura e das novas ferramentas das quais a Administração Pública pode dispor, Giulio Napolitano recorda que as "ferramentas de ação unilateral não são as únicas disponíveis para a administração, embora, por muito tempo, tenham sido as mais importantes ou ao menos visíveis". Emerge como alternativa, na percepção de Giulio Napolitano, os diversos tipos de acordo que a Administração Pública pode

(RERE), Salvador, Instituto Brasileiro de Direito Público, no. 24, dezembro, janeiro, fevereiro, 2011.

10 OLIVEIRA, Gustavo Henrique Justino de; SCHWANKA, C. A administração consensual como a nova face da Administração Pública no século XXI: fundamentos dogmáticos, formas de expressão e instrumentos de ação. A\&C. Revista da Faculdade de Direito da Universidade de São Paulo, v. 104, p. 303-322, 2008. p. 309.

11 PALMA, Juliana Bonacorsi de. Sanção e acordo na Administração Pública. São Paulo: Malheiros, 2015. p. 111.

12 PALMA, Juliana Bonacorsi de. Sanção e acordo na Administração Pública. p. 111.

13 OLIVEIRA, Gustavo Henrique Justino de; SCHWANKA, C. A administração consensual como a nova face da Administração Pública no século XXI: fundamentos dogmáticos, formas de expressão e instrumentos de ação. p. 305. 
NIEBUHR, Pedro de Menezes; OLIVEIRA, Cláudio Ladeira de; QUINT, Gustavo Ramos da Silva. Relação entre a consensualidade administrativa e o modelo cooperativo do processo civil brasileiro: o contexto de criação das câmaras de mediação e conciliação na administração pública. Revista Eletrônica Direito e Política, Programa de Pós-Graduação Stricto Sensu em Ciência Jurídica da UNIVALI, Itajaí, v.13, n.3, $3^{0}$ quadrimestre de 2018. Disponível em: www.univali.br/direitoepolitica - ISSN 1980-7791

travar com seus parceiros. ${ }^{14}$

No Direito estrangeiro, principalmente na Europa, a consensualidade já é uma realidade e uma diretriz sedimentada nos ordenamentos jurídicos de alguns países como a Itália, Alemanha e a Espanha. ${ }^{15}$ Juliana Bonacorsi de Palma relata, por exemplo, que o artigo 11 da Lei de Processo Administrativo italiano (Lei n. 241/1990) autoriza o recurso a acordos com terceiros para "finalizar o conteúdo discricionário do ato final ou substituí-lo desde que a prática consensual não cause prejuízo a terceiros e nem afaste a Administração do dever de satisfazer o interesse público". ${ }^{16} \mathrm{~A}$ lei italiana, através de acordos integrativos e substitutivos, tornou o agir administrativo mais flexível e propenso "a figuras atípicas de exercício da função administrativa". ${ }^{17}$

Já no Direito espanhol, por sua vez, o artigo 88 da Lei de Processo Administrativo autoriza o que se chama de "terminação convencional" do processo. O objetivo é conferir à Administração novas perspectivsa, com a possibilidade de celebrar acordos (em sentido amplo) como forma consensual de resolução dos litígios que fizer parte. ${ }^{18}$

Como corolário da expressão consensualidade, Gustavo Justino de Oliveira destaca a concertação administrativa e a contratualização administrativa. Em sua concepção, uma atuação concertada seria aquela pautada pela ampla participação dos particulares na tomada de decisão junto à Administração Pública. Como consequência, a contratualização caracteriza-se pela substituição do ato administrativo unilateral para acordos bilaterais, fundados no diálogo. ${ }^{19}$

14 No original: "Gli strumenti di azione unilaterale no sono gli unici a disposizione dell'amministrazione, sebbene per lungo tempo siano stati quelli più importanti o comunque quelli più visibili. L'amministrazione, infatti, può anche concludere diversi tipi di accordi con i suoi interlocutori, pubblici a privati". NAPOLITANO, Giulio. La logica del diritto amministrativo. Il Mulino, Bologna, 2014. p. 175 (tradução livre).

15 PALMA, Juliana Bonacorsi de. Sanção e acordo na Administração Pública. p. 100.

16 PALMA, Juliana Bonacorsi de. Sanção e acordo na Administração Pública. p. 100.

17 PALMA, Juliana Bonacorsi de. Sanção e acordo na Administração Pública. p. 102.

18 PALMA, Juliana Bonacorsi de. Sanção e acordo na Administração Pública. p. 107.

19 OLIVEIRA, Gustavo Henrique Justino de; SCHWANKA, C. A administração consensual como a nova face da Administração Pública no século XXI: fundamentos dogmáticos, formas de expressão e instrumentos de ação. p. 315. 
NIEBUHR, Pedro de Menezes; OLIVEIRA, Cláudio Ladeira de; QUINT, Gustavo Ramos da Silva. Relação entre a consensualidade administrativa e o modelo cooperativo do processo civil brasileiro: o contexto de criação das câmaras de mediação e conciliação na administração pública. Revista Eletrônica Direito e Política, Programa de Pós-Graduação Stricto Sensu em Ciência Jurídica da UNIVALI, Itajaí, v.13, n.3, $3^{\circ}$ quadrimestre de 2018. Disponível em: www.univali.br/direitoepolitica - ISSN 1980-7791

No Brasil a consensualidade vai, em diversos âmbitos da Administração, se consolidando. A título de exemplo, Gustavo Justino de Oliveira elenca o acordo na desapropriação, os compromissos de ajustamento de condutas das ações civis públicas, os acordos em contratos administrativos, a leniência no âmbito do CADE e o contrato de gestão. ${ }^{20}$

A existência de dispositivos legais autorizadores de soluções consensuais é pontual, de modo que não altera a posição da Administração Pública como uma das maiores litigantes do Poder Judiciário. Dados de 2011 do Conselho Nacional de Justiça demonstram que órgãos e entidades da Administração Pública, em suas três esferas, representam, somados, cerca de $51 \%$ das ações judiciais em andamento no país. Desse percentual, em 59\% das ações a fazenda pública encontra-se no polo passivo. Os gráficos abaixo dão uma breve noção dessa dimensão:

Gráfico 1 - Percentual de processos dos 100 maiores litigantes nacionais por setor.

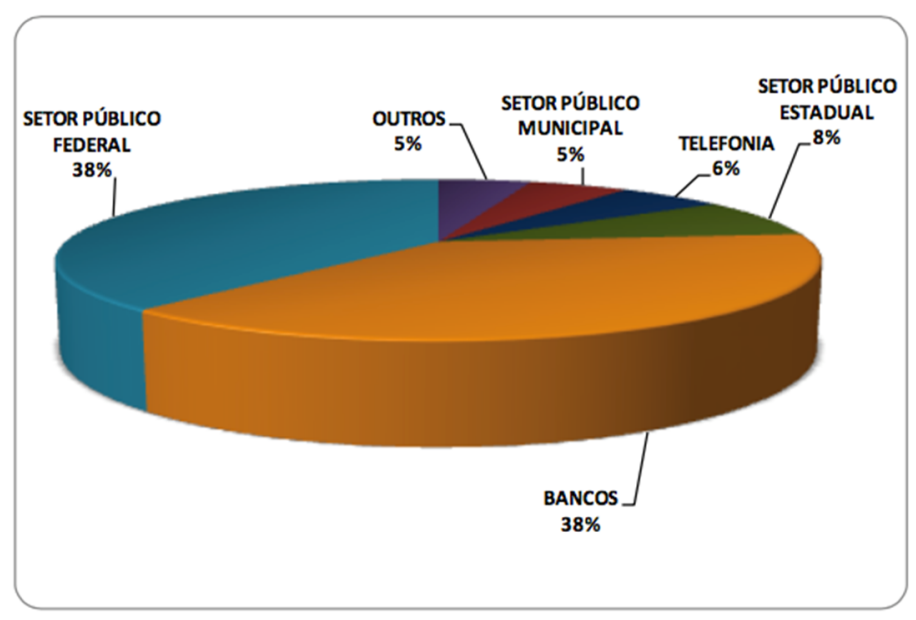

Gráfico 2 - Quantitativo do total de processos dos 100 maiores litigantes nacionais com percentual entre os polos ativo e passivo.

20 OLIVEIRA, Gustavo Henrique Justino de; SCHWANKA, C. A administração consensual como a nova face da Administração Pública no século XXI: fundamentos dogmáticos, formas de expressão e instrumentos de ação. p. 318. 
NIEBUHR, Pedro de Menezes; OLIVEIRA, Cláudio Ladeira de; QUINT, Gustavo Ramos da Silva. Relação entre a consensualidade administrativa e o modelo cooperativo do processo civil brasileiro: o contexto de criação das câmaras de mediação e conciliação na administração pública. Revista Eletrônica Direito e Política, Programa de Pós-Graduação Stricto Sensu em Ciência Jurídica da UNIVALI, Itajaí, v.13, n.3, $3^{\circ}$ quadrimestre de 2018. Disponível em: www.univali.br/direitoepolitica - ISSN 1980-7791

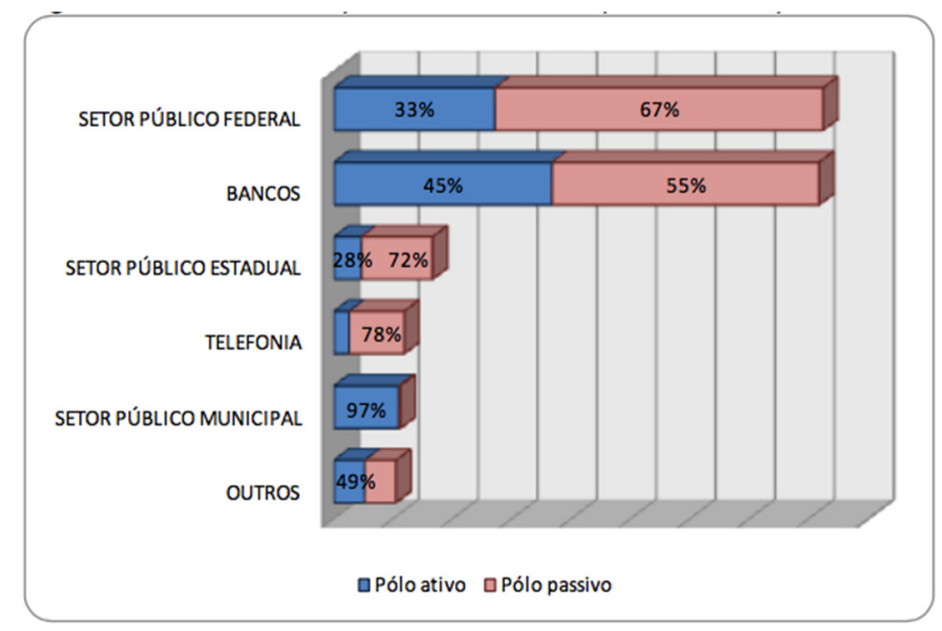

Fonte: BRASIL. Conselho Nacional de Justiça. 100 maiores litigantes. Brasília, 2011.

Os dados apontam a existência de um problema pungente. ${ }^{21}$ Nesse contexto, 0 aprimoramento e a implementação de mecanismos consensuais aplicáveis a todas as dimensões e esferas da Administração Pública é medida necessária e patente, o que evidencia a importância de pesquisas nessa área com vistas a oferecer soluções concretas a um problema que atinge toda a sociedade. Nesse sentido, são precisas as lições de Diogo Figueiredo Moreira Neto:

Pela consensualidade, o Poder Público vai além de estimular a prática de condutas privadas de interesse público, passando a estimular a criação de soluções privadas de interesse público, concorrendo para enriquecer seus modos e formas de atendimento.

É como acrescentar às potencialidades da máquina burocrática as infinitas potencialidades da sociedade e de

\footnotetext{
21 Em adendo: "Pesquisa realizada pelo CNJ, no ano de 2009, constatou a existência de 82.9 milhões de processos em curso. Praticamente, toda a população brasileira estaria a litigar se considerarmos processos com pelo menos duas partes e um número de 190 milhões de habitantes no Brasil (Antonio Aurélio Abi-Ramia Duarte. Flexibilização procedimental nos juizados especiais estaduais. Rio de Janeiro: JC, 2014). Outro dado, agora relativo aos juizados especiais no Estado do Rio de Janeiro, releva um crescimento vertiginoso do número de processos com a diminuição do número de acordos. No ano de 1998, as conciliações chegavam a 30\%, tendo diminuído para $24 \%$ em 2005 e a 16\% em 2011. (Paulo Cezar Pinheiro Carneiro. Acesso à justiça: Juizados Especiais Cíveis e Ação Civil Pública. 2. ed. Rio de Janeiro: Forense, 2003 e Antonio Aurélio Abi-Ramia Duarte. Flexibilização procedimental nos juizados especiais estaduais. Op. Cit.) Em: CARNEIRO, Paulo Cezar Pinheiro. Comentários ao artigo 30. In: ARRUDA ALVIM WAMBIER, Teresa; et al. Breves comentários ao código de processo civil. 3. ed. rev. e atual. Revista dos Tribunais, 2016. p. 81 .
} 
NIEBUHR, Pedro de Menezes; OLIVEIRA, Cláudio Ladeira de; QUINT, Gustavo Ramos da Silva. Relação entre a consensualidade administrativa e o modelo cooperativo do processo civil brasileiro: o contexto de criação das câmaras de mediação e conciliação na administração pública. Revista Eletrônica Direito e Política, Programa de Pós-Graduação Stricto Sensu em Ciência Jurídica da UNIVALI, Itajaí, v.13, n.3, $3^{0}$ quadrimestre de 2018. Disponível em: www.univali.br/direitoepolitica - ISSN 1980-7791

suas miríades de organizações sociais, que deixa de ser mera súdita para ser sócia e parceira da atuação estatal, passando a ter no consenso e não na coerção a primeira das opções relacionais. ${ }^{22}$

Esta ideia estriba-se, em grande parte, na releitura dos princípios da indisponibilidade do interesse público e da legalidade.

Atualmente, tem-se cada vez mais clara percepção de que o interesse público não é contraposto ao interesse privado, nem cujo dever de zelo é monopólio estatal. ${ }^{23}$ Diversas análises indicam que a Administração Pública e os particulares são, juntos, capazes de buscar a satisfação do interesse público das mais variadas formas ${ }^{24}$, inclusive atuando cooperativamente. $O$ interesse público também pode ser realizado por meio da satisfação do interesse privado.

No que toca à legalidade, no paradigma clássico, a noção surgiu com o intuito de pautar a atuação do soberano com amparo na lei, evitando arbitrariedades e insegurança jurídica. ${ }^{25}$ Notadamente para a Administração Pública, Odete Medauar sustenta que, sob o viés que vigorou durante todo o século XIX, a legalidade poderia ser concebida sob dois aspectos. $O$ primeiro deles diz respeito a uma visão mecanicista, de amoldamento das condutas à norma, na medida em que a Administração seria, em suas palavras, uma mera executora da lei. ${ }^{26} \mathrm{O}$ segundo aspecto seria o de que a noção de legalidade resumir-se-ia em submissão à lei formal, aquela editada pelo parlamento. ${ }^{27}$

Não obstante, referida tradição formalista, baseada essencialmente na centralidade da lei, dá lugar à abertura constitucional do Direito Administrativo. Transparece-se com isso, o que denomina de "crise da lei formal e da noção da legalidade". Demanda-se da Administração Pública uma nova postura, respalda

22 MOREIRA NETO, Diogo de Figueiredo. Novos institutos consensuais da ação administrativa. Revista de Direito Administrativo, Rio de Janeiro, n. 231, p. 129-156, jan./mar. 2003. p. 156. 23 OLIVEIRA, Gustavo Henrique Justino de; SCHWANKA, C. A administração consensual como a nova face da Administração Pública no século XXI: fundamentos dogmáticos, formas de expressão e instrumentos de ação. p. 305.

24 Para aprofundamento, ver OLIVEIRA, Gustavo Justino de. Contrato de gestão. São Paulo: Revista dos Tribunais, 2008.

25 SILVA, Vasco Pereira da. O contencioso administrativo no divã da psicanálise: ensaio sobre as acções no novo processo administrativo. 2. ed. atual. Coimbra: Almedina, 2009. p. 21.

26 MEDAUAR, Odete. O direito administrativo em evolução. p. 166.

27 MEDAUAR, Odete. O direito administrativo em evolução. p. 169. 
NIEBUHR, Pedro de Menezes; OLIVEIRA, Cláudio Ladeira de; QUINT, Gustavo Ramos da Silva. Relação entre a consensualidade administrativa e o modelo cooperativo do processo civil brasileiro: o contexto de criação das câmaras de mediação e conciliação na administração pública. Revista Eletrônica Direito e Política, Programa de Pós-Graduação Stricto Sensu em Ciência Jurídica da UNIVALI, Itajaí, v.13, n.3, $3^{\circ}$ quadrimestre de 2018. Disponível em: www.univali.br/direitoepolitica - ISSN 1980-7791

pela sua vinculação à juridicidade em detrimento da superada vinculação positiva à lei em sentido estrito. A vinculação, nesse sentido, é ao ordenamento, compreendendo uma atuação conforme as disposições constitucionais, a atos normativos infralegais, e a princípios gerais de direito.

É nessa conjuntura de abertura da Administração Pública às reais demandas e necessidades da sociedade, que a crise de lei formal, com a "substituição da legalidade estrita pelo princípio da juridicidade"28 como norte de atuação permite que se adotem novos instrumentos racionais, modernos e consensuais de solução de conflitos e de amoldamento de interesses. ${ }^{29}$

2 MUdANÇA DE PARADIGMA NO PROCESSO CIVIL BRASILEIRO: A COOPERAÇÃO NO CódIGO DE PROCESSO CIVIL DE 2015 E AS CÂMARAS DE MEDIAÇÃo E CONCILIAÇÃo NA ADMINISTRAÇÃo PÚBLICA COMO EXPRESSÃO DA CONSENSUALIDADE

\subsection{Os modelos processuais e a cooperação no Código de Processo Civil}

Mudanças também alcançam o processo civil brasileiro e têm estreita relação com as transformações que vêm sendo percebidas no Direito Administrativo.

A doutrina processualista costuma dividir os modelos de tradição processual em três (adversarial, inquisitorial e cooperativo ${ }^{30}$ ), classificados de acordo com os "pressupostos sociais, lógicos e éticos"31 de determinada sociedade. Cada um dos

28 NIEBUHR, Pedro de Menezes. Processo administrativo ambiental: Teoria, modalidades e aspectos controvertidos. 2. ed. Rio de Janeiro: Lumen Juris, 2017. p. 2017. p. 83.

29 MEDAUAR, Odete. O direito administrativo em evolução. p. 174.

30 Denominação adotada por Fredie Didier Jr.. Daniel Mitidiero, por outro lado, classifica-os em modelos isonômico, assimétrico e cooperativo. As características são essencialmente as mesmas. Em: DIDIER JR., Fredie. Os três modelos de direito processual: inquisitivo, dispositivo e cooperativo. Revista de Processo, v. 198/2011. p. 213-226. ago. 2011.

31 Anota Daniel Mitidiero: "Do ponto de vista social, o Estado Constitucional de modo nenhum pode ser confundido com o Estado-Inimigo. Nessa quadra, assim como a sociedade pode ser compreendida como um empreendimento de cooperação entre os seus membros visando à obtenção de proveito mútuo, também o Estado deixa de ter um papel de pura abstenção e passa a ter que prestar positivamente para cumprir com seus deveres constitucionais. Do ponto de vista lógico, o processo cooperativo pressupõe o reconhecimento do caráter problemático do Direito, reabilitando a sua feição argumentativa. Passa-se da lógica apodítica à lógica dialética. Finalmente, do ponto de vista ético, o processo pautado pela colaboração é um processo orientado pela busca, 
NIEBUHR, Pedro de Menezes; OLIVEIRA, Cláudio Ladeira de; QUINT, Gustavo Ramos da Silva. Relação entre a consensualidade administrativa e o modelo cooperativo do processo civil brasileiro: o contexto de criação das câmaras de mediação e conciliação na administração pública. Revista Eletrônica Direito e Política, Programa de Pós-Graduação Stricto Sensu em Ciência Jurídica da UNIVALI, Itajaí, v.13, n.3, $3^{0}$ quadrimestre de 2018. Disponível em: www.univali.br/direitoepolitica - ISSN 1980-7791

modelos processuais diz respeito uma forma diferente de conduzir o processo ao atribuir diferentes "funções de trabalho" a cada um dos atores. ${ }^{32}$ Em essência, os modelos estudam o papel do juiz e das partes no processo.

De saída, constata-se que os modelos não são melhores ou piores aprioristicamente. Estão em conformidade com o devido processo legal, cujo significado varia de acordo com tempo e espaço e, essencialmente, com o sistema jurídico em que está inserido. ${ }^{33}$ Alguns sistemas encaixaram-se melhor em determinados contextos, enquanto outros não.

Pois bem. O modelo adversarial, como o próprio nome sugere, é pautado principalmente por uma lógica de competição entre as partes. A atividade processual é conduzida preponderantemente pelas partes, que assumem a posição de protagonistas na instrução processual. A atividade processual, nesse modelo, é "coisa das partes", de modo que o juiz ocupa um papel passivo. Falase em princípio dispositivo ${ }^{34}$ como fundamento desse modelo processual, pelo qual, através de um exercício argumentativo-retórico, as partes "descobrem" o direito sob uma base de contraditório isonômico. ${ }^{35}$

Nesse viés de processo como duelo, "o destino da causa ficava na dependência pura e simples do desempenho das partes na defesa de seus interesses e na produção dos elementos de prova". ${ }^{36}$ Admite-se, inclusive, que o juiz não seja um amplo conhecedor do sistema jurídico, cabendo às partes trazer todos os argumentos a fim de convencê-lo.

\footnotetext{
tanto quanto possível, da verdade, e que, para além de emprestar relevo à boa-fé subjetiva, também exige de todos os seus participantes a observância da boa-fé objetiva, sendo igualmente seu destinatário o juiz" Em: MITIDIERO, Daniel. Processo justo, colaboração e ônus da prova. Revista do TST. Brasília. p. 67-77. v. 78. n 1. jan. mar. 2012. p. 69-70.

32 MITIDIERO, Daniel. Bases para construção de um processo civil cooperativo: o direito processual civil no marco teórico do formalismo-valorativo. 2007. 147 f. Tese (Doutorado em Direito) - Curso de Programa de Pós-graduação em Direito, Universidade Federal do Rio Grande do Sul, Porto Alegre, 2007.p. 72.

33 DIDIER JR., Fredie. Os três modelos de direito processual: inquisitivo, dispositivo e cooperativo. p. 213.

${ }^{34}$ Princípio não no sentido normativo, mas como orientação, fundamento. Em: DIDIER JR., Fredie. Os três modelos de direito processual: inquisitivo, dispositivo e cooperativo. p. 214.

35 MITIDIERO, Daniel. Bases para construção de um processo civil cooperativo: o direito processual civil no marco teórico do formalismo-valorativo. p. 73.

36 THEODORO JÚNIOR, Humberto. et. al. Novo CPC: Fundamentos e sistematização. Rio de Janeiro: Forense, 2015. p. 62.
} 
NIEBUHR, Pedro de Menezes; OLIVEIRA, Cláudio Ladeira de; QUINT, Gustavo Ramos da Silva. Relação entre a consensualidade administrativa e o modelo cooperativo do processo civil brasileiro: o contexto de criação das câmaras de mediação e conciliação na administração pública. Revista Eletrônica Direito e Política, Programa de Pós-Graduação Stricto Sensu em Ciência Jurídica da UNIVALI, Itajaí, v.13, n.3, $3^{\circ}$ quadrimestre de 2018. Disponível em: www.univali.br/direitoepolitica - ISSN 1980-7791

No modelo inquisitorial ${ }^{37}$, por sua vez, "o magistrado passa a gozar de amplos poderes na condução do processo, assumindo em definitivo a sua direção". ${ }^{38}$ Aqui o juiz é o protagonista e o direito, diferente de ser descoberto, já está posto pelo Estado. Cabe ao juiz subsumir os fatos ao direito, extraindo a norma jurídica no caso concreto. O debate das partes, noutro giro, é relegado ao segundo plano.

Esse modelo é bastante marcado pela ideia de que o direito não existe fora do âmbito do Estado e a atividade processual é preponderantemente conduzida por magistrado com amplos poderes, inclusive, para determinar a produção probatória de ofício (o que sequer podia ser concebido no panorama adversarial).

A questão é que os dois sistemas não estão necessariamente incompatíveis entre si. No processo civil brasileiro há equilíbrio entre essas duas formas, na medida em que em algumas matérias o legislador conferiu maiores traços de dispositividade (instauração do processo e fixação do objeto litigioso) e, em outras, maior inquisitoriedade (investigação probatória, efeito devolutivo dos recursos).

Recentemente, a literatura especializada tem se detido sob um terceiro modelo, o cooperativo. O modelo cooperativo nasce no seio de um Estado Constitucional que busca uma "sociedade livre, justa e solidária". ${ }^{39}$

O Código de Processo Civil de 2015 consolidou-o expressamente, em seu artigo 60, ao dispor que "[t]odos os sujeitos do processo devem cooperar entre si para que se obtenha, em tempo razoável, decisão de mérito justa e efetiva". Perceba que não se trata de mera faculdade, mas de verdadeiro dever de todos os agentes envolvidos.

\footnotetext{
37 Diz-se esse modelo como fruto da socialização processual em detrimento da característica liberal do processo dipositivo, movimento que ganha força no século XX por conta do Welfare State. Em: THEODORO JÚNIOR, Humberto. et. al. Novo CPC: Fundamentos e sistematização. p. 62-63.

38 MITIDIERO, Daniel. Bases para construção de um processo civil cooperativo: o direito processual civil no marco teórico do formalismo-valorativo. p. 73.

39 MITIDIERO, Daniel. Bases para construção de um processo civil cooperativo: o direito processual civil no marco teórico do formalismo-valorativo. p. 75-76.
} 
NIEBUHR, Pedro de Menezes; OLIVEIRA, Cláudio Ladeira de; QUINT, Gustavo Ramos da Silva. Relação entre a consensualidade administrativa e o modelo cooperativo do processo civil brasileiro: o contexto de criação das câmaras de mediação e conciliação na administração pública. Revista Eletrônica Direito e Política, Programa de Pós-Graduação Stricto Sensu em Ciência Jurídica da UNIVALI, Itajaí, v.13, n.3, $3^{\circ}$ quadrimestre de 2018. Disponível em: www.univali.br/direitoepolitica - ISSN 1980-7791

O papel do juiz, no modelo cooperativo, é redesenhado, passa a assumir uma dupla posição. De um lado, tem-se um juiz "paritário no diálogo", ou seja, que prima pelo dever de cooperação e diálogo com as partes e deve obediência principalmente aos deveres de "esclarecimento, consulta, prevenção e auxílio". ${ }^{40}$ A isonomia reside na condução do processo. ${ }^{41}$ De outro, persiste a posição de assimetria no momento de decidir. Nas palavras de Fredie Didier Jr., as decisões do juiz são resultado da "atividade processual em cooperação... A atividade cognitiva é compartilhada mas a decisão é manifestação do poder, que é exclusivo do órgão jurisdicional". 42

Mesmo reconhecendo que as partes têm ampla liberdade para desenhar e participar ativamente do rumo do processo, o ato de decidir ainda é preponderantemente jurisdicional (traços da concepção hierárquica ${ }^{43}$ de jurisdição e publicista de processo ${ }^{44}$ ). É um ato de poder do Estado. Em suma, não é dada às partes a possibilidade de tomar a decisão no lugar do magistrado. 45

Da mesma forma, a cooperação no processo civil pressupõe a superação da visão do processo como relação triangular. ${ }^{46}$ O processo torna-se, na verdade, uma relação complexa na medida em que as partes, o magistrado, os serventuários da justiça e demais atores, todos, passam a ter posição de protagonista na solução do conflito no caso concreto. É o que se denomina "comunidade de trabalho". 47

\footnotetext{
40 MITIDIERO, Daniel. Bases para construção de um processo civil cooperativo: o direito processual civil no marco teórico do formalismo-valorativo. p. 55.

41 MITIDIERO, Daniel. Bases para construção de um processo civil cooperativo: o direito processual civil no marco teórico do formalismo-valorativo. p. 73.

42 DIDIER JR., Fredie. Os três modelos de direito processual: inquisitivo, dispositivo e cooperativo. p. 216.

43 DAMASKA, Myrjan R. The Faces of Justice and State Authority: a comparative approach to the legal process. Yale University Press, 1991. p. 18-19.

44 MITIDIERO, Daniel. Bases para construção de um processo civil cooperativo: o direito processual civil no marco teórico do formalismo-valorativo. p. 50.

45 DIDIER JR., Fredie. Curso de direito processual civil. v. 1. 19. ed. rev. amp. e atual. Salvador: Jus Podivm. 2017, p. 142.

46 LAMY, Eduardo de Avelar; RODRIGUES, Horácio Wanderlei. Teoria Geral do Processo. 4. Ed. São Paulo: Atlas. 2016. p. 23-26.

47 THEODORO JÚNIOR, Humberto. et. al. Novo CPC: Fundamentos e sistematização. p. 62.
} 
NIEBUHR, Pedro de Menezes; OLIVEIRA, Cláudio Ladeira de; QUINT, Gustavo Ramos da Silva. Relação entre a consensualidade administrativa e o modelo cooperativo do processo civil brasileiro: o contexto de criação das câmaras de mediação e conciliação na administração pública. Revista Eletrônica Direito e Política, Programa de Pós-Graduação Stricto Sensu em Ciência Jurídica da UNIVALI, Itajaí, v.13, n.3, $3^{0}$ quadrimestre de 2018. Disponível em: www.univali.br/direitoepolitica - ISSN 1980-7791

Cumpre evitar aderir a uma visão romântica e ingênua de cooperação. ${ }^{48}$ Afinal, em um litígio as partes geralmente estão em posição de contraposição de interesses, e muitas vezes indispostas a cooperar com a parte contrária. Da mesma forma, os magistrados e os servidores em geral tem rotina atribulada e assoberbada de ações judiciais pendentes de decisão ou de cumprimento. Há, também, fatores externos como metas do Conselho Nacional do Justiça e índices de produtividade, que podem desencorajar um engajamento cooperativo entre os sujeitos processuais.

A rigor, não se pretende, com a cooperação, que uma parte litigante ajude a outra a satisfazer seus interesses particulares. Não é isso que está em causa. A cooperação, a partir de uma interpretação sistemática do Código de Processo Civil, parece dizer respeito muito mais à necessidade de observância de um contraditório substancial, da vedação da decisão surpresa, da primazia do julgamento do mérito, dos deveres de boa-fé e lealdade processual, bem como na fundamentação das decisões judiciais. ${ }^{49}$ Relaciona-se, enfim, à condução do processo e não ao mérito da causa. Esse pensamento é sintetizado nas palavras de Daniel Mitidiero:

A colaboração estrutura-se a partir da previsão de regras que devem ser seguidas pelo juiz na condução do processo. O juiz tem os deveres de esclarecimento, de diálogo, de prevenção e de auxílio para com os litigantes. É assim que funciona a cooperação. Esses deveres consubstanciam as regras que estão sendo enunciadas quando se fala em colaboração no processo. A doutrina é tranquila a respeito do assunto. 50

\footnotetext{
48 Coaduna-se com a posição de Humberto Theodoro Junior em: THEODORO JÚNIOR, Humberto. et. al. Novo CPC: Fundamentos e sistematização. p. 62.

${ }^{49}$ Abra-se parênteses para esclarecer que, tal qual no processo judicial, a cooperação também é pressuposto do processo administrativo. Como anota Pedro de Menezes Niebuhr: "Uma última implicação do pressuposto da cooperação tem relação à postura que se espera da própria Administração. Viabilizar uma efetiva cooperação entre os atores envolvidos importa, também, disponibilização de condições para tal desiderato, postura que depende, em grande medida, do Poder Público. Dois exemplos são paradigmáticos desta problemática: a disponibilização da informação e a proteção à confiança que se deposita na Administração". (NIEBUHR, Pedro de Menezes. Processo administrativo ambiental: Teoria, modalidades e aspectos controvertidos. p. 157).

${ }^{50}$ DIDIER JR., Fredie. Os três modelos de direito processual: inquisitivo, dispositivo e cooperativo. p. 216.
} 
NIEBUHR, Pedro de Menezes; OLIVEIRA, Cláudio Ladeira de; QUINT, Gustavo Ramos da Silva. Relação entre a consensualidade administrativa e o modelo cooperativo do processo civil brasileiro: o contexto de criação das câmaras de mediação e conciliação na administração pública. Revista Eletrônica Direito e Política, Programa de Pós-Graduação Stricto Sensu em Ciência Jurídica da UNIVALI, Itajaí, v.13, n.3, $3^{\circ}$ quadrimestre de 2018. Disponível em: www.univali.br/direitoepolitica - ISSN 1980-7791

Uma das manifestações da cooperação no processo civil consiste no estímulo à resolução consensual de conflitos, principalmente através dos mecanismos de mediação, conciliação e de transação judicial. O respeito à liberdade das partes de elegerem a melhor forma de conduzir o processo é, nesse contexto, ínsito à cooperação. ${ }^{51}$

O Código de Processo Civil atribuiu relevância ímpar à consensualidade, tornoua norma fundamental do processo civil (art. $3^{\circ}$, $\S \S 20$ e $3^{\circ}$ ) e dedicou um capítulo exclusivamente à matéria ${ }^{52}$, a ponto de Fredie Didier Jr. entender que o "sistema de direito processual civil brasileiro é, enfim, estrurado no sentido de estipular a autocomposição". 53

Nesse campo - da consensualidade - o Código de Processo Civil aproxima-se sobremaneira ao Direito Administrativo, principalmente na valorização da vontade das partes, com enfoque na contratualização e nos acordos, em detrimento de um sistema rígido e formal, de via única de atuação. O sistema de resolução de conflitos estabelecido no Código de Processo Civil ${ }^{54}$ caminha harmoniosamente, lado a lado, com o novo paradigma consensual do Direito Administrativo.

\subsection{Pontos de contato entre o Direito Processual Civil e o Direito} Administrativo: as câmaras de conciliação e mediação com a Administração Pública

Alguns dispositivos do Código de Processo Civil expressam o fenômeno da consensualidade administrativa.

O artigo 174 do Código de Processo Civil previu que os entes federativos (União, Estados, Distrito Federal e Municípios) devem criar câmaras de conciliação e mediação, a fim de facilitar a solução consensual de conflitos.

\footnotetext{
51 Fredie Didier Jr. denomina essa liberdade de "princípio do respeito ao autorregramento da vontade no processo". (DIDIER JR., Fredie. Curso de direito processual civil. p. 151).

52 DIDIER JR., Fredie. Curso de direito processual civil, p. 151.

53 DIDIER JR., Fredie. Curso de direito processual civil. p. 151.

${ }^{54}$ Apesar de diversos mecanismos já existirem na legislação esparsa, a matéria ganhou especial destaque após a publicação do Código de Processo Civil de 2015.
} 
NIEBUHR, Pedro de Menezes; OLIVEIRA, Cláudio Ladeira de; QUINT, Gustavo Ramos da Silva. Relação entre a consensualidade administrativa e o modelo cooperativo do processo civil brasileiro: o contexto de criação das câmaras de mediação e conciliação na administração pública. Revista Eletrônica Direito e Política, Programa de Pós-Graduação Stricto Sensu em Ciência Jurídica da UNIVALI, Itajaí, v.13, n.3, $3^{\circ}$ quadrimestre de 2018. Disponível em: www.univali.br/direitoepolitica - ISSN 1980-7791

José Antônio Dias Toffoli credita a previsão das câmaras de conciliação e mediação feita no artigo 174 do Código de Processo Civil à experiência ocorrente em modelos já consolidados de câmaras de concliação no âmbito da Administração Pública, como é o caso da Câmara de Conciliação e Arbitragem da Administração Federal (CCAF). A Câmara de Conciliação e Arbitragem da Administração Federal, integrante da Consultoria-Geral da União, foi criada em 2007 por meio do Ato Regimental no 05/07 e da Portaria AGU 1.281/07. O autor relata casos em que a Câmara de Conciliação e Arbitragem da Administração Federal logrou êxito em viabilizar solução consensual em litígios que extravasavam o âmbito patrimonial, como foi o caso da controvérsia jurídica entre a Funai e o Incra em relação à divergência de interesses na demarcação da Terra Indígena Guajajara Vila Real, no Maranhão. Desde sua criação, em 2007, o autor narra ter havido a instalação de mais de 200 câmaras de conciliação no âmbito da Advocacia Geral da União, previnindo a instauração de centenas de litígios judiciais e o gasto de vultosas somas de recursos ${ }^{55}$.

A intenção do Código é louvável, busca dar mais racionalidade ao sistema jurídico e aproximar a Administração do particular. ${ }^{56}$ Essa aproximação possibilita ao cidadão "resolver o conflito de forma dialógica e não imposta por um terceiro, como é o caso do Poder Judiciário". ${ }^{77}$ É consentânea, portanto, ao novo paradigma administrativo tratado na seção anterior.

O Código de Processo Civil utilizou-se da expressão "criarão". Significa dizer que não há margem de liberdade, ou discricionariedade, para se optar ou não pela criação das câmaras. Trata-se de um dever, uma obrigação determinada por lei. Isso, evidentemente, não significa que todo conflito deva ser obrigatoriamente resolvido nessas câmaras. As câmaras devem ser criadas, devem existir, para facilitar a solução consensual de conflitos.

55 TOFFOLI, José Antônio Dias. Movimento conciliatório e a Câmara de Conciliação e Arbitragem da Administração Federal (CCAF): breves considerações. Revista de Arbitragem e Mediação, vol. 50 , p. 229 - 240, Jul-Set 2016.

56 ASSIS, Araken de. Processo civil brasileiro, v. 1. Parte geral: fundamentos e distribuição de conflitos. São Paulo: Revista dos Tribunais, 2015. p. 98.

57 PEIXOTO, Ravi. A nova sistemática de resolução consensual de conflitos pelo poder público: uma análise a partir do CPC/2015 e da lei 13.140/2015. Revista de Processo. v. 261/2016. p. 467497. nov. 2016. p. 473. 
NIEBUHR, Pedro de Menezes; OLIVEIRA, Cláudio Ladeira de; QUINT, Gustavo Ramos da Silva. Relação entre a consensualidade administrativa e o modelo cooperativo do processo civil brasileiro: o contexto de criação das câmaras de mediação e conciliação na administração pública. Revista Eletrônica Direito e Política, Programa de Pós-Graduação Stricto Sensu em Ciência Jurídica da UNIVALI, Itajaí, v.13, n.3, $3^{\circ}$ quadrimestre de 2018. Disponível em: www.univali.br/direitoepolitica - ISSN 1980-7791

A obrigação imposta pelo artigo 174 do Código de Processo Civil é dirigida, como dito, aos entes federados. O Código de Processo Civil não explicita como essa obrigação deve ser executada, notadamente a que estrutura as câmaras devem ser ligadas e serão disponibilizadas à população. Por exemplo, o Código de Processo Civil não diz se as câmaras devem estar vinculadas ao Poder Executivo ou se podem integrar a estrutura do Poder Judiciário. Trata-se de circunstância de especial relevância, posto que se necessariamente integrante da estrutura da Administração Pública, as câmaras poderiam encontrar óbice para serem criadas no âmbito de pequenos municípios, em função de limitações orçamentárias para estruturação física, de pessoal e manutenção. Nada impede, é verdade, que elas sejam instaladas em ambiente compartilhado dentro de uma mesma estrutura administrativa, mas também não há empecilho, aprioristico, para que elas sejam alocadas nos foruns judiciais, aproveitando a estrutura já disponível nas comarcas do Poder Judiciário. A obrigação, repisa-se, é dirigida ao ente federado, que deve dispor de estrutura para resolver o litígio ainda no âmbito administrativo, independentemente da judicialização da controvérsia.

Dentre as principais funções das câmaras, elencadas nos incisos do artigo 174, destacam-se:

a) Dirimir conflitos envolvendo órgãos e entidades da administração pública (conflitos de competência entre órgãos de fiscalização, p. ex.); b) avaliar a admissibilidade dos pedidos de resolução de conflitos, por meio de conciliação, no âmbito da administração pública (pedidos de parcelamento de dívidas fiscais, p. ex); c) promover, quando couber, a celebração de termo de ajustamento de conduta, instrumento negocial importante a solução de conflitos coletivos (art. 50, § 60, Lei n. 7.347/1985). ${ }^{58}$

Consoante defende Ravi Peixoto, o rol do artigo 174 é meramente exemplificativo59, como sugere a partir final do caput, diante do uso da expressão "tais como". Isso amplia, potencialmente, a utilização dos mecanismos consensuais como forma de dirimir boa parte dos conflitos existentes entre entes

\footnotetext{
58 DIDIER JR., Fredie. Curso de direito processual civil.. p. 315.

59 PEIXOTO, Ravi. A nova sistemática de resolução consensual de conflitos pelo poder público: uma análise a partir do CPC/2015 e da lei 13.140/2015.
} 
NIEBUHR, Pedro de Menezes; OLIVEIRA, Cláudio Ladeira de; QUINT, Gustavo Ramos da Silva. Relação entre a consensualidade administrativa e o modelo cooperativo do processo civil brasileiro: o contexto de criação das câmaras de mediação e conciliação na administração pública. Revista Eletrônica Direito e Política, Programa de Pós-Graduação Stricto Sensu em Ciência Jurídica da UNIVALI, Itajaí, v.13, n.3, $3^{0}$ quadrimestre de 2018. Disponível em: www.univali.br/direitoepolitica - ISSN 1980-7791

da Administração Pública ou entre esta e particulares, salvo expressa disposição legal em sentido contrário. Não se limita a conflitos patrimoniais e abre-se espaço para a resolução tanto de conflitos judiciais como extrajudiciais, consante entendimento externado no Enunciado no 398 do Fórum Permanente de Processualistas Civis. 60

A previsão da mediação e conciliação no âmbito da Administração Pública, feita pelo Código de Processo Civil, é completada pelo artigo 175, que prevê que as disposições naquela lei não excluem outras formas de concliação e mediação extrajudiciais vinculadas a órgãos institucionais ou realizadas por intermédio de profissionais independentes; e que os dispositivos daquela lei se aplicam, no que couber, às câmaras privadas de conciliação e mediação.

\subsection{A Lei no 13.140/15}

O tratamento, sintético, do assunto, na forma regulada pelo Código de Processo Civil, foi complementado pela Lei no 13.140/15, que trata da mediação e da autocomposição de conflitos no âmbito da Administração Pública. Dentre as previsões Lei no $13.140 / 15$ da que merecem destaque, menciona-se o §o $1^{0}$ do artigo 32, que estabelece que o funcionamento das câmaras e procedimentalização dos mecanismos de autocomposição dar-se-ão de acordo com regulamento a ser editado pelo respectivo ente federativo, o que dá ampla margem para que os mecanismos consensuais sejam adaptados à realidade de cada lugar (noção de lógica difusa da sociedade de Gustavo Justino ${ }^{61}$ ). Também vale menção que, na forma do $\S 3^{\circ}$ do artigo 32, o acordo firmado terá força de

\footnotetext{
60 "Enunciado 398: As câmaras de conciliação e mediação têm competência para realização de conciliação, no âmbito administrativo, de conflitos judiciais e extrajudiciais".

61 Para o autor: "A principal consequiência na organização estatal é a premência de nela serem instituídos canais e mecanismos de percepção e participação social, sob pena de tornar insubsistente toda e qualquer ação estatal que ao final possa resultar, direta ou indiretamente, em benefícios à população. A constatação de que o corpo social encontra-se ordenado em redes exige que o Estado imprima maior capilaridade aos órgãos e entidades integrantes da arquitetura administrativa. Urge que isso ocorra, notadamente com o intuito de facilitar a absorção e a internalização das demandas oriundas da sociedade, processo que tornará mais qualificadas as políticas públicas, os programas, os projetos e demais ações de Estado, as quais visam satisfazer tais demandas." Em: OLIVEIRA, Gustavo Henrique Justino de; SCHWANKA, C. . A administração consensual como a nova face da Administração Pública no século XXI: fundamentos dogmáticos, formas de expressão e instrumentos de ação. p. 307.
} 
NIEBUHR, Pedro de Menezes; OLIVEIRA, Cláudio Ladeira de; QUINT, Gustavo Ramos da Silva. Relação entre a consensualidade administrativa e o modelo cooperativo do processo civil brasileiro: o contexto de criação das câmaras de mediação e conciliação na administração pública. Revista Eletrônica Direito e Política, Programa de Pós-Graduação Stricto Sensu em Ciência Jurídica da UNIVALI, Itajaí, v.13, n.3, $3^{\circ}$ quadrimestre de 2018. Disponível em: www.univali.br/direitoepolitica - ISSN 1980-7791

título executivo extrajudicial e que a instauração do procedimento consensual suspende a prescrição (artigo 34).

O artigo 35 da Lei no 13.140/15 prevê que as "controvérias jurídicas que envolvam a administração pública federal direta, suas autarquias e fundações poderão ser objeto de transação por adesão [...]". De um lado a solução consensual por adesão pode ser interessante em demandas repetitivas ${ }^{62}$. É o que se viu, por exemplo, no caso dos acordos por adesão para recompor as perdas da poupanca provocadas pelos planos econômicos da década de 80 e $90^{63}$, cuja expectativa é atender mais de cinquenta mil beneficiados.

De outro lado, deve-se ter em mente que a solução por adesão não é, propriamente, uma solução de mediação. Nela não há espaço para consenso ou negociação. A Administração Pública está, muitas das vezes, em uma condição de superioridade em relação ao particular; nessa posição, é ela quem define os termos do acordo, cabendo ao particular somente aderir ou não. ${ }^{64} \mathrm{~A}$ adesão é uma técnica de transação, que deve ter lugar, portanto, nos casos em que a controvérsia é, efetivamente repetitiva, reclamando um tratamento isonômico entre os particulares em situação equivalente.

\section{CONSIDERAÇÕES FINAIS}

A abertura à consensualidade na Adminstração Pública é uma tendência e mostra-se cada vez mais necessária diante dos problemas trazidos pelo antigo paradigma de atuação da atividade administrativa, marcada por traços fortes de autoridade. Mecanismos consensuais permitem a adoção de soluções mais democráticas e racionais, que pode realizar de forma presumidamente mais adequada, em dados casos, a satisfação do interesse público.

A tônica de consensualidade e de cooperação também ganhou força no processo civil brasileiro, o que se denota pelas normas fundamentais e pelos diversos

62 PEIXOTO, Ravi. A nova sistemática de resolução consensual de conflitos pelo poder público: uma análise a partir do CPC/2015 e da lei 13.140/2015.

63 https://www.pagamentodapoupanca.com.br/

64 PEIXOTO, Ravi. A nova sistemática de resolução consensual de conflitos pelo poder público: uma análise a partir do CPC/2015 e da lei 13.140/2015. 
NIEBUHR, Pedro de Menezes; OLIVEIRA, Cláudio Ladeira de; QUINT, Gustavo Ramos da Silva. Relação entre a consensualidade administrativa e o modelo cooperativo do processo civil brasileiro: o contexto de criação das câmaras de mediação e conciliação na administração pública. Revista Eletrônica Direito e Política, Programa de Pós-Graduação Stricto Sensu em Ciência Jurídica da UNIVALI, Itajaí, v.13, n.3, $3^{\circ}$ quadrimestre de 2018. Disponível em: www.univali.br/direitoepolitica - ISSN 1980-7791

mecanismos insculpidos na legislação processual. Dá-se enfoque à cooperação entre todos os atores do processo e aos mecanismos de soluções consensuais, tais como a mediação e a conciliação.

O Código de Processo Civil influi sobre o Direito Administrativo neste ponto, tornando obrigatória a criação de câmaras de mediação e conciliação na Administração Pública para facilitar a busca da solução consensual de controvérsias. Trata-se de importante passo para a concretização do consenso no âmbito administrativo.

A Lei no 13.140/15, que trata da mediação e da autocomposição de conflitos no âmbito da Administração Pública avançou ainda mais, detalhando diversas nuances da mediação e da transação, de modo geral, em matéria administrativa. Cumpre ao intérprete dar a melhor aplicação ao referido arcabouço normativo para se realizar de forma mais adequada o propósito de consensualidade na Administração Pública.

\section{REFERÊNCIAS DAS FONTES CITADAS}

ALFONSO, Luciano Parejo. Derecho Administrativo. Barcelona: Ariel, 2003

ASSIS, Araken de. Processo civil brasileiro, v. 1. Parte geral: fundamentos e distribuição de conflitos. São Paulo: Revista dos Tribunais, 2015.

ARRUDA ALVIM WAMBIER, Teresa; et al. Breves comentários ao código de processo civil. 3. ed. rev. e atual. Revista dos Tribunais, 2016.

Decreto n. 7.392, de 13 de dezembro de 2010. Aprova a Estrutura

Regimental e o Quadro Demonstrativo dos Cargos em Comissão da AdvocaciaGeral da União, aprova o Quadro Demonstrativo dos Cargos em Comissão da Procuradoria-Geral Federal e remaneja cargos em comissão para a AdvocaciaGeral da União e para a Procuradoria-Geral Federal. Diário Oficial da República Federativa do Brasil, Brasília, DF, 14 de dezembro de 2010. Disponível em: 
NIEBUHR, Pedro de Menezes; OLIVEIRA, Cláudio Ladeira de; QUINT, Gustavo Ramos da Silva. Relação entre a consensualidade administrativa e o modelo cooperativo do processo civil brasileiro: o contexto de criação das câmaras de mediação e conciliação na administração pública. Revista Eletrônica Direito e Política, Programa de Pós-Graduação Stricto Sensu em Ciência Jurídica da UNIVALI, Itajaí, v.13, n.3, $3^{\circ}$ quadrimestre de 2018. Disponível em: www.univali.br/direitoepolitica - ISSN 1980-7791

http://www.planalto.gov.br/ccivil_03/_Ato2007-

2010/2010/Decreto/D7392.htm?TSPD_101_R0=e19e26cdc0072152dede42fdfc1 468bavS10000000000000000d22a2bb1ffff00000000000000000000000000005a efb666004303aa8f

. Lei n. 8.987, de 13 de fevereiro de 1995. Dispõe sobre o regime de concessão e permissão da prestação de serviços públicos previstos no art. 175 da Constituição Federal, e dá outras providências. Diário Oficial da República Federativa do Brasil, Brasília, DF, 14 de fevereiro de 1995. Disponível em: http://www.planalto.gov.br/ccivil_03/leis/L8987cons.htm

Lei n. 13.105, de 16 de março de 2015. Código de Processo Civil. Diário Oficial da República Federativa do Brasil, DF, 17 de março de 2015. Disponível em: http://www.planalto.gov.br/ccivil_03/_ato2015-2018/2015/lei/l13105.htm

Lei n. 13.140, de 26 de junho de 2015. Dispõe sobre a mediação entre particulares como meio de solução de controvérsias e sobre a autocomposição de conflitos no âmbito da administração pública; altera a Lei no 9.469, de 10 de julho de 1997, e o Decreto no 70.235, de 6 de março de 1972; e revoga o § 20 do art. 60 da Lei no 9.469, de 10 de julho de 1997. Diário Oficial da República Federativa do Brasil, DF, 29 de junho de 2015. Disponível em: http://www.planalto.gov.br/ccivil_03/_ato2015-2018/2015/lei//13140.htm

\section{CRISTÓVAM, José Sérgio da Silva. Administração pública democrática e}

supremacia do interesse público: novo regime jurídico-administrativo e seus princípios constitucionais estruturantes. Curitiba: Juruá, 2015.

DAMASKA, Myrjan R. The Faces of Justice and State Authority: a comparative approach to the legal process. Yale University Press, 1991.

DIDIER JR., Fredie. Curso de direito processual civil. v. 1. 19. ed. rev. amp. e atual. Salvador: Jus Podivm. 2017. 
NIEBUHR, Pedro de Menezes; OLIVEIRA, Cláudio Ladeira de; QUINT, Gustavo Ramos da Silva. Relação entre a consensualidade administrativa e o modelo cooperativo do processo civil brasileiro: o contexto de criação das câmaras de mediação e conciliação na administração pública. Revista Eletrônica Direito e Política, Programa de Pós-Graduação Stricto Sensu em Ciência Jurídica da UNIVALI, Itajaí, v.13, n.3, $3^{\circ}$ quadrimestre de 2018. Disponível em: www.univali.br/direitoepolitica - ISSN 1980-7791

DIDIER JR., Fredie. Os três modelos de direito processual: inquisitivo, dispositivo e cooperativo. Revista de Processo, v. 198/2011. P. 225-251. ago. 2011.

LAMY, Eduardo de Avelar; RODRIGUES, Horácio Wanderlei. Teoria Geral do Processo. 4. Ed. São Paulo: Atlas. 2016.

MEDAUAR, Odete. O direito administrativo em evolução. 3. ed. Brasília, DF: Gazeta Jurídica, 2017.

\section{MITIDIERO, Daniel. Bases para construção de um processo civil}

cooperativo: o direito processual civil no marco teórico do formalismovalorativo. 2007. 147 f. Tese (Doutorado em Direito) - Curso de Programa de Pós-graduação em Direito, Universidade Federal do Rio Grande do Sul, Porto Alegre, 2007.

MOREIRA NETO, Diogo de Figueiredo. Mutações do Direito Administrativo. Rio de Janeiro: Renovar, 2000.

MOREIRA NETO, Diogo de Figueiredo. Novos institutos consensuais da ação administrativa. Revista de Direito Administrativo, Rio de Janeiro, n. 231, p. 129-156, jan./mar. 2003.

NAPOLITANO, Giulio. La logica del diritto amministrativo. Il Mulino, Bologna, 2014.

NIEBUHR, Pedro de Menezes. Processo administrativo ambiental: Teoria, modalidades e aspectos controvertidos. 2. ed. Rio de Janeiro: Lumen Juris, 2017.

OLIVEIRA, Gustavo Henrique Justino de; SCHWANKA, C.. A administração consensual como a nova face da Administração Pública no século XXI: fundamentos dogmáticos, formas de expressão e instrumentos de ação. A\&C. Revista da Faculdade de Direito da Universidade de São Paulo, v. 104, p. 303-322, 2008. 
NIEBUHR, Pedro de Menezes; OLIVEIRA, Cláudio Ladeira de; QUINT, Gustavo Ramos da Silva. Relação entre a consensualidade administrativa e o modelo cooperativo do processo civil brasileiro: o contexto de criação das câmaras de mediação e conciliação na administração pública. Revista Eletrônica Direito e Política, Programa de Pós-Graduação Stricto Sensu em Ciência Jurídica da UNIVALI, Itajaí, v.13, n.3, $3^{\circ}$ quadrimestre de 2018. Disponível em: www.univali.br/direitoepolitica - ISSN 1980-7791

OLIVEIRA, Gustavo Justino de. Contrato de gestão. São Paulo: Revista dos Tribunais, 2008.

PALMA, Juliana Bonacorsi de. Sanção e acordo na Administração Pública. São Paulo: Malheiros, 2015.

PEIXOTO, Ravi. A nova sistemática de resolução consensual de conflitos pelo poder público: uma análise a partir do CPC/2015 e da lei 13.140/2015. Revista de Processo. v. 261/2016. p. 467-497. nov. 2016.

SCHIRATO, Vitor Rhein. PALMA, Juliana Bonacorsi de. Consenso e Legalidade: vinculação da Atividade Administrativa Consensual ao Direito. Revista Eletrônica sobre a Reforma do Estado (RERE), Salvador, Instituto Brasileiro de Direito Público, no. 24, dezembro, janeiro, fevereiro, 2011.

SILVA, Vasco Pereira da. O contencioso administrativo no divã da psicanálise: ensaio sobre as acções no novo processo administrativo. 2. ed. atual. Coimbra: Almedina, 2009

THEODORO JÚNIOR, Humberto. et. al. Novo CPC: Fundamentos e sistematização. Rio de Janeiro: Forense, 2015.

TOFFOLI, José Antônio Dias. Movimento conciliatório e a Câmara de Conciliação e Arbitragem da Administração Federal (CCAF): breves considerações. Revista de Arbitragem e Mediação, vol. 50, p. 229 - 240, Jul-Set 2016.

Recebido em: 05/10/2018

Aprovado em: 20/11/2018 